\title{
CT and MR imaging features in phosphaturic mesenchymal tumor-mixed connective tissue: A case report
}

\author{
ZHENSHAN SHI $^{1 *}$, YIQIONG DENG ${ }^{2 *}$, XIUMEI LI ${ }^{1}$, YUEMING LI $^{1}$, \\ DAIRONG CAO $^{1}$ and VIKASH SAHADEO COOSSA ${ }^{3}$ \\ ${ }^{1}$ Department of Radiology, First Affiliated Hospital of Fujian Medical University; \\ ${ }^{2}$ Department of Radiology, Fuzhou Children's Hospital; ${ }^{3}$ Fujian Medical University, Fuzhou, Fujian 350005, P.R. China
}

Received July 12, 2017; Accepted December 19, 2017

DOI: $10.3892 / 01.2018 .7945$

\begin{abstract}
Phosphaturic mesenchymal tumor-mixed connective tissue (PMT-MCT) is rare and usually benign and slow-growing. The majority of these tumors is associated with sporadic tumor-induced osteomalacia (TIO) or rickets, affect middle-aged individuals and are located in the extremities. Previous imaging studies often focused on seeking the causative tumors of TIO, not on the radiological features of these tumors, especially magnetic resonance imaging (MRI) features. PMT-MCT remains a largely misdiagnosed, ignored or unknown entity by most radiologists and clinicians. In the present case report, a review of the known literature of PMT-MCT was conducted and the CT and MRI findings from three patient cases were described for diagnosing the small subcutaneous tumor. Typical MRI appearances of PMT-MCT were isointense relative to the muscles on T1-weighted imaging, and markedly hyperintense on T2-weighted imaging containing variably flow voids, with markedly heterogeneous/homogenous enhancement on post contrast T1-weighted fat-suppression imaging. Short time inversion recovery was demonstrated to be the optimal sequence in localizing the tumor.
\end{abstract}

\section{Introduction}

Phosphaturic mesenchymal tumor (PMT) is a polymorphous group of extremely rare mesenchymal tumors that often result in hypophosphatemic osteomalacia/rickets, caused by the overproduction of the phosphaturic hormone fibroblast growth factor 23 (FGF23) (1-7). PMTs occur more frequently in

Correspondence to: Dr Dairong Cao, Department of Radiology, First Affiliated Hospital of Fujian Medical University, 20 Cha-Zhong Road, Fuzhou, Fujian 350005, P.R. China

E-mail: shizhenshan@fjmu.edu.cn

\section{${ }^{*}$ Contributed equally}

Key words: oncogenic osteomalacia, phosphaturic mesenchymal tumor, magnetic resonance imaging, computed tomography middle-aged adults, although the age of the patients can range from 3 to 73 years, and are originated predominantly from soft tissue or bone involving a single site $(8,9)$. The vast majority of PMTs are benign, small, subcutaneous and undetectable on physical examination (10-12). The female to male ratio in patients with PMT is 1:1.2. The most common subtype of PMT is the mixed connective tissue, which accounts for $>70 \%$ of cases (13).

Historically, it has been documented that many kinds of mesenchymal neoplasms have been classically associated with tumor-induced osteomalacia (TIO) $(14,15)$. TIO, also known as oncogenic osteomalacia, is a rare paraneoplastic syndrome in which vitamin D-resistant osteomalacia occurs due to the presence of a tumor (16). Therefore, in addition to distinguishing the four different histological subtypes of PMTs previously described (17), it is more important to discriminate this neoplasm from other vascular tumors preoperatively. Furthermore, these tumors frequently occur in variable odd locations making discovery very difficult. As a consequence, these tumors remain a largely misdiagnosed, ignored or unknown entity by most radiologists and clinicians.

Owing to the rarity of PMT, our knowledge of imaging features of this entity has come mostly from the context of case reports or very small case series in the endocrinology, osteology, nuclear medicine, and pathology literature. There have been $>300$ cases of PMTs described in the literature so far (16). While many of these studies have focused on the pathologic characterization and whole-body imaging modalities of choice in the investigation of PMTs, to the best of our knowledge, there have been no prior reports on the computed tomography (CT) and magnetic resonance imaging (MRI) features of PMTs in the radiology literature. Based on clinical and laboratory examination, musculoskeletal radiologists can originally make the diagnosis of PMTs given the typical CT and MRI findings, but unfortunately the diagnosis has appeared to be often delayed in the radiology community.

To overcome this diagnostic problem, the current study discusses three cases of PMT-MCT in the soft tissue using routine MRI examination. All three patients presented with nonspecific clinical presentation, including diffuse pain, myalgia, muscle spasms, muscle weakness and fatigue. In the current case report, the CT and MRI findings of the three patient cases, for diagnosing the soft-tissue tumor, are 
described. Furthermore, a comprehensive review of the clinicopathological features of PMTs that have been previously reported in the medical literature is discussed.

\section{Case report}

Case 1. A 59-year-old male presented with a five-year history of fatigue and generalized muscle pain (Table I). He was admitted to the First Affiliated Hospital of Fujian Medical University (Fuzhou, China) in August 2016. The long-term muscle pain became increasingly worse with temporary relief from physiotherapy and analgesics. Routine blood test was performed at the time of admission with the results of hypophosphatemia, normal calcium and parathyroid hormone (PTH) levels (Table II). Slightly elevated cystatin-C and an elevation of alkaline phosphatase (ALP) were noted (Table II). The preoperative bone metabolism markers were presented in Table III. A clinical diagnosis of hypophosphatemic osteomalacia of unknown etiology was considered and treatment with oral phosphorus and high-dose vitamin D was initiated. A whole-body Tc bone scintigraphy scan was performed as a first step and no lesions were identified. Additional whole-body ${ }^{18}$ F-fludeoxyglucose (FDG) positron emission tomography (PET)/CT scan was ordered to detect the causative tumor. A promising focus of intense FDG uptake was detected in the right ankle (Fig. 1). The $\mathrm{CT}$ scan revealed a small round homogeneous soft-tissue mass, which was located between the distal end of the tibia and fibula and thought to be a PMT (Fig. 2). Subsequent MRI revealed a small subcutaneous tumor $(1.2 \times 1.1 \times 0.9 \mathrm{~cm})$, which appeared isointense to the muscles on T1-weighted imaging, slightly hyperintense on T2-weighted imaging, markedly hyperintense on short tau inversion recovery (STIR) coronal imaging (Fig. 3), and displayed homogeneous enhancement on postcontrast T1-weighted fat-suppression imaging (Fig. 4). The tumor was radically resected and diagnosed as PMT-MCT pathologically (Fig. 5; Table IV). Table V lists the levels of postoperative bone mentalism markers and ALP at 8 months following surgery. Muscle pain was relieved quickly after the operation, and serum phosphorus levels gradually recovered to normal.

Case 2. A 52-year-old female presented with left posterior chest pain for the duration of ten years. She was admitted to the First Affiliated Hospital of Fujian Medical University (Fuzhou, China) in July 2008. Further physical examination revealed a large left chest wall tumor involving the 9-11th ribs. The serum bone metabolism markers were presented in Table III. A whole-body Tc bone scintigraphy scan was used to identify a potential tumor of osteomalacia. An area of abnormal absence of uptake in the 10th rib and slight increased uptake in the 9th and 11th rib were observed. The patient was subsequently referred for plain CT and contrast-enhanced MRI scans for evaluation. The axial $\mathrm{CT}$ of the chest revealed a large poorly circumscribed mass $(14 \times 9 \times 8 \mathrm{~cm})$. The lesion appeared heterogeneously hypointense on T1WI, hyperintense on fat-saturated T2WI containing prominent vascular flow voids, and marked heterogeneous enhancement on fat-saturated T1-weighted sequences (Fig. 6). Surgical resection of the lesion was conducted, and the pathologic findings confirmed a PMT-MCT with no evidence of malignancy (Fig. 7; Table IV). Table V lists the levels of postoperative bone mentalism markers and ALP at 8 months following surgery. The patient recovered well during the postoperative period, and the chest pain diminished over time. Furthermore, preoperative serum phosphate levels were marked low at $0.38 \mathrm{mmol} / 1$ (normal range, $0.81-1.55 \mathrm{mmol} / \mathrm{l}$ ) and the levels normalized to $1.1 \mathrm{mmol} / \mathrm{l}$ at 2 months after the surgery (Table II).

Case 3. A 59-year-old female presented with left chest muscle spasms with pain which worsened progressively for the duration of one year. She was admitted to the First Affiliated Hospital of Fujian Medical University (Fuzhou, China) in April 2016. On admission, no significant abnormality was observed on physical examination. No muscle atrophy was found initially. Laboratory data disclosed hypophosphatemia with a serum phosphorus level of $0.68 \mathrm{mmol} / \mathrm{l}$ (normal range, 0.81-1.55 mmol/l), with normal serum PTH and calcium levels (Table II). Urinary excretion of phosphorus over $24 \mathrm{~h}$ increased to $8.91 \mathrm{mmol} / 1$ (normal range, 0.96-1.62 $\mathrm{mmol} / \mathrm{l}$ ).

Radiographs of her bones revealed diffused demineralization and DEXA bone densitometry scan revealed marked decrease of bone density in both lumbar spine $(0.751 \mathrm{~g} / \mathrm{cm} 2$; T-score, -3.6) and left femoral neck $\left(0.439 \mathrm{~g} / \mathrm{cm}^{2}\right.$; T-score, -4.5$)$. A whole-body Tc bone scintigraphy scan was performed and it demonstrated a focal area of increased uptake in the 10th rib. The patient began taking phosphorus and high-dose vitamin D orally. One month later, her condition did not improve considerably. Extensive radiology evaluation including CT and MR scan was performed. Axial CT scan revealed a small soft-tissue mass $(1.5 \times 1.5 \times 0.5 \mathrm{~cm})$ in the lower posterior chest wall. The neoplasm appeared homogeneously isointense on T1WI, hyperintense on fat-saturated T2WI (Fig. 8), and marked homogeneous enhancement on fat-saturated T1-weighted sequences. Subsequent surgical resection was conducted, and the neoplasm was removed and the surgical specimen was pathologically diagnosed to be a PMT-MCT (Fig. 9; Table IV). Four days after the operation serum phosphorus levels normalized to $0.82 \mathrm{mmol} / \mathrm{l}$, and one month after the operation muscle pain was completely relieved. Table $\mathrm{V}$ lists the levels of postoperative ALP at 8 months after surgery.

\section{Discussion}

Clinicopathological features and tumor detection. The clinical symptoms of PMTs are nonspecific and typically include, but not limited to, diffused pain, muscle weakness, pathologic bone fracture, motor weakness, skeletal deformities, height loss and generalized debilitated state secondary to osteomalacia (18-24). In addition, patients often present with a firm, slow-growing, unpalatable soft-tissue mass when the tumors arise within the extremities (25-27). Approximately 53\% of reported cases occur in the bone, $\sim 45 \%$ in soft tissue, and $2 \%$ in the skin (28-32). The typical biochemical parameters are hypophosphatemia resulting from renal phosphate wasting, an inappropriately low serum 1,25-dihydroxyvitamin $\mathrm{D}_{3}$, normal 25-hydroxyvitamin $\mathrm{D}_{3}$, normal or slightly low serum calcium and elevated ALP levels (8,25,33-35). The clinical and biochemical characteristics of the patients presented in the current report were similar to those observed in previously published literature, in which the tumor was situated elsewhere 

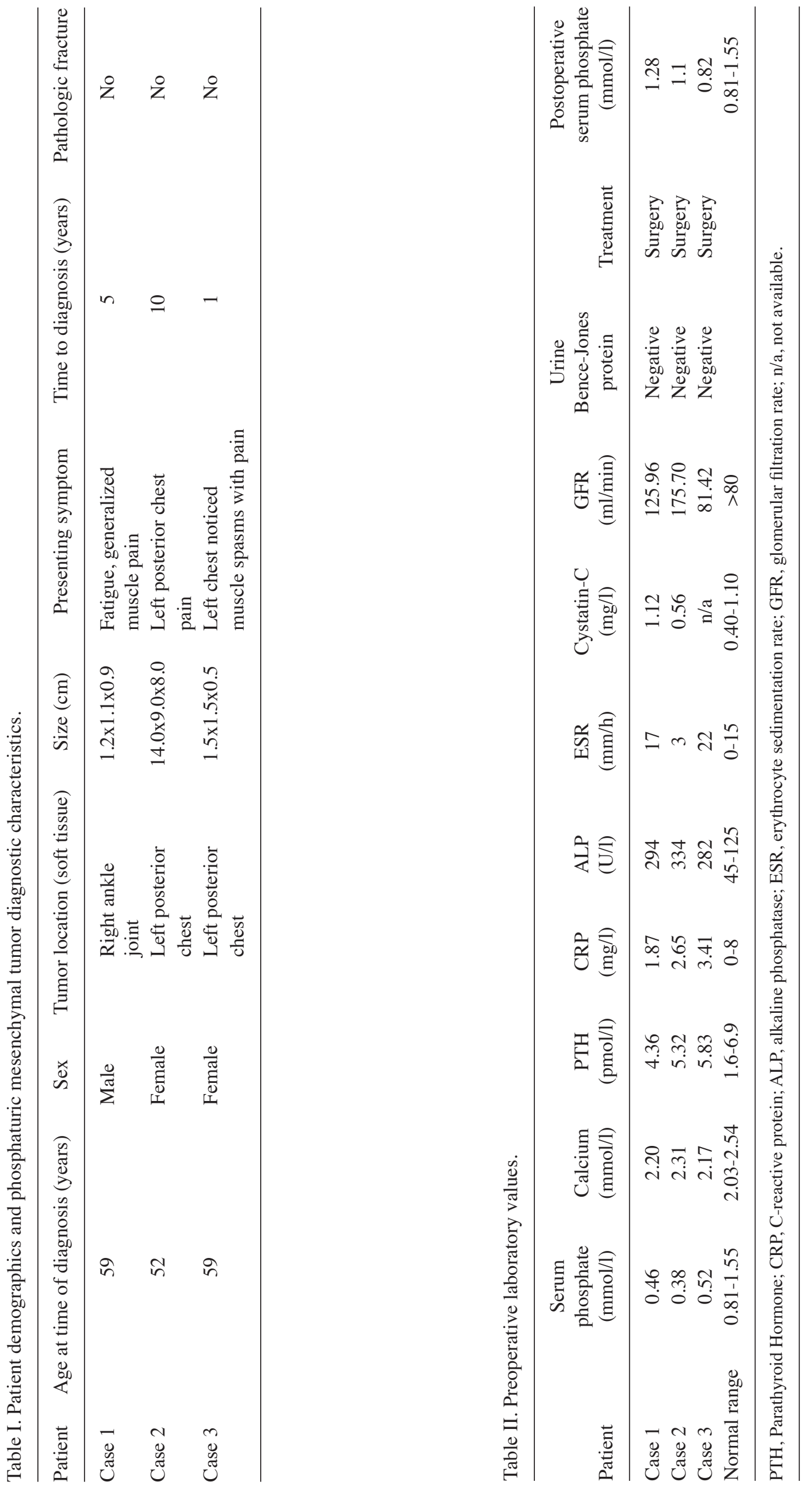
Table III. Preoperative bone mentalism markers.

\begin{tabular}{|c|c|c|c|c|}
\hline Patient & $\begin{array}{l}\text { Total } 25 \text {-hydroxy } \\
\text { vitamin D (ng/ml) }\end{array}$ & $\begin{array}{l}\text { Osteocalcin } \\
(\mathrm{ng} / \mathrm{ml})\end{array}$ & $\begin{array}{c}\text { Beta-CrossLaps } \\
(\mathrm{ng} / \mathrm{ml})\end{array}$ & TPINP (ng/ml) \\
\hline Case 1 & 35.09 & 33.09 & 0.95 & 103.60 \\
\hline Case 2 & 5.6 & 19.77 & 0.599 & 39.61 \\
\hline Normal range & $\begin{array}{l}\text { 20-70 (<5 marked decrease; } \\
\text { 5-10 modest decrease; } \\
\text { 10-20 slight decrease; } \\
>200 \text { intoxication) }\end{array}$ & $14-46$ & $0-0.704$ & $\begin{array}{l}\text { 16.89-65.491 } \\
\text { (pre-menopause, 5.13-58.59; } \\
\text { post-menopause with HRT treatment, } \\
\text { 14.28-58.92; post-menopause without } \\
\text { HRT treatment, 20.25-76.31) }\end{array}$ \\
\hline
\end{tabular}

TPINP, total procollagen type $1 \mathrm{~N}$-terminal propeptide; HRT, hormone replacement therapy.

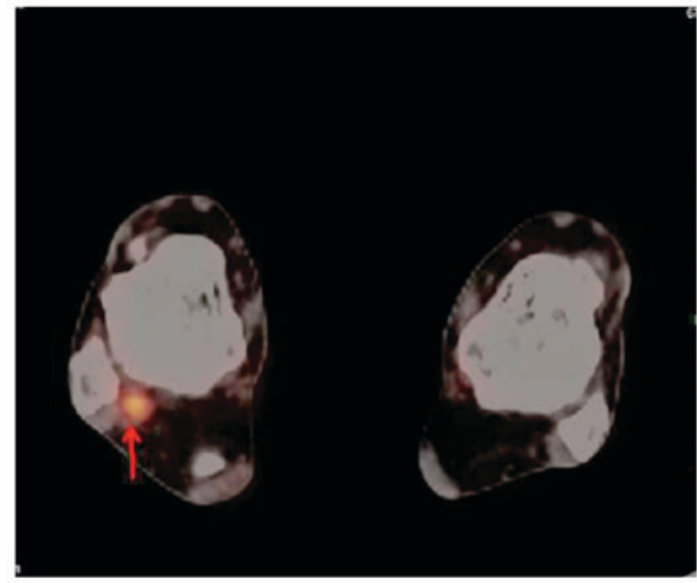

Figure 1. Axial ${ }^{18} \mathrm{~F}$-FDG PET/CT scan reveals a small subcutaneous focus of intense FDG uptake (red arrow) in the right ankle. FDG, fludeoxyglucose; $\mathrm{PET} / \mathrm{CT}$, positron emission tomography/computed tomography.

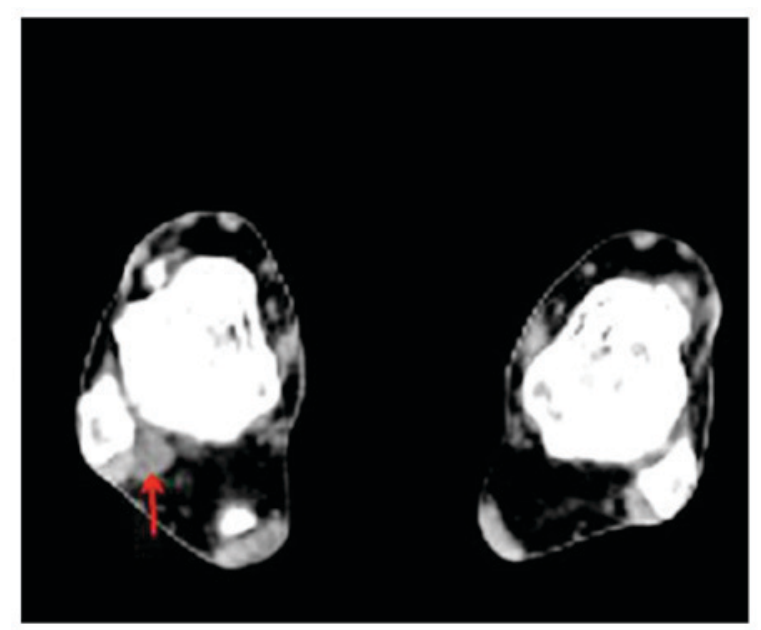

Figure 2. Computed tomography scan reveals a small round homogeneous isodense soft-tissue mass $(1.2 \times 1.1 \times 0.9 \mathrm{~cm}$; red arrow) located between the distal end of the tibia and fibula.

in the body. In case 1 , a slightly elevated serum Cystatin- $C$ was also observed, associated with renal tubule damage.

Pathologically, four morphologic patterns of PMTs have been described and widely accepted: primitive-appearing

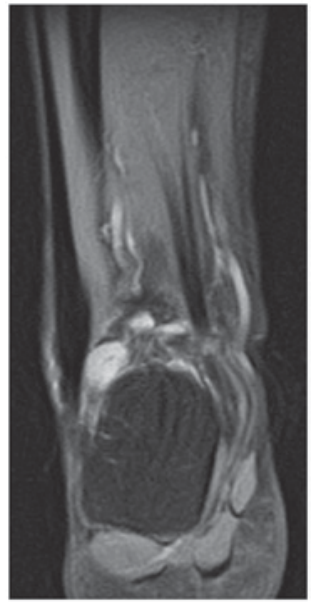

Figure 3. A phosphaturic mesenchymal tumor-mixed connective tissue with small tumor size appears markedly uniform hyperintense on short tau inversion recovery coronal imaging.

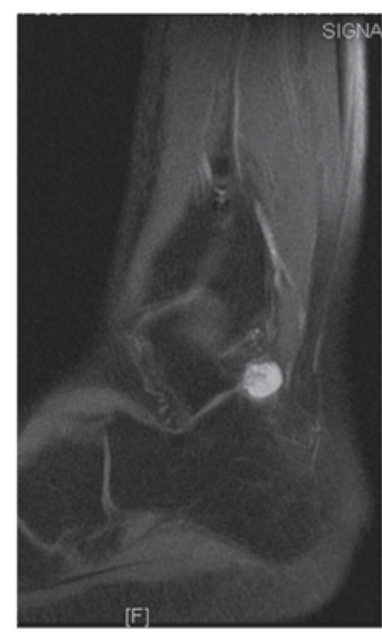

Figure 4. A phosphaturic mesenchymal tumor-mixed connective tissue displays homogeneous vivid enhancement on postcontrast T1-weighted fat-suppression imaging.

mixed connective tissue, osteoblastoma-like, nonossifying fibroma-like, and ossifying fibroma-like $(10,11,17,36,37)$. It is now believed that the latter three variants may reflect 
Table IV. Pathological features and imaging modalities.

\begin{tabular}{|c|c|c|c|c|c|c|c|c|c|c|c|c|}
\hline \multirow[b]{2}{*}{ Patient } & \multirow{2}{*}{$\begin{array}{l}\text { Histopathological } \\
\text { diagnosis }\end{array}$} & \multicolumn{10}{|c|}{ Immunohistochemical findings } & \multirow[b]{2}{*}{ Imaging } \\
\hline & & BCL2 & Vimentin & CD68 & CD56 & SMA & CK & P63 & EMA & KI67 & S-100 & \\
\hline Case 1 & PMT-MCT & + & + & + & + & - & - & - & - & $+5 \%$ & - & $\begin{array}{l}\text { Tc bone scintigraphy+ } \\
\text { PET/CT+MRI }\end{array}$ \\
\hline Case 2 & PMT-MCT & & + & + & + & - & - & & - & $+5 \%$ & - & $\begin{array}{l}\text { Tc bone } \\
\text { scintigraphy+CT+MRI }\end{array}$ \\
\hline Case 3 & PMT-MCT & + & + & + & + & + & - & + & & $2 \%$ & & $\begin{array}{l}\text { Tc bone } \\
\text { scintigraphy+CT+MRI }\end{array}$ \\
\hline
\end{tabular}

PMT-MCT, phosphaturic mesenchymal tumors-mixed connective tissue; SMA, smooth muscle actin; CK, cytokeratin; P63, tumor protein 63; EMA, epithelial membrane antigen; PET/CT, positron emission tomography/computed tomography; MRI, magnetic resonance imaging.

Table V. Postoperative (8 months) bone mentalism marker and ALP levels.

\begin{tabular}{|c|c|c|c|c|c|}
\hline Patient & $\begin{array}{l}\text { Total } 25 \text {-hydroxy } \\
\text { vitamin D }(\mathrm{ng} / \mathrm{ml})\end{array}$ & $\begin{array}{l}\text { Osteocalcin } \\
(\mathrm{ng} / \mathrm{ml})\end{array}$ & $\begin{array}{l}\text { beta-CrossLaps } \\
(\mathrm{ng} / \mathrm{ml})\end{array}$ & TPINP (ng/ml) & $\begin{array}{l}\text { ALP } \\
(\mathrm{U} / \mathrm{l})\end{array}$ \\
\hline Case 1 & 28.27 & 35.12 & 0.65 & 38.27 & 199 \\
\hline Case 2 & 9.25 & 17.54 & 0.43 & 39.61 & 223 \\
\hline Case 3 & - & - & - & - & 207 \\
\hline Normal range & $\begin{array}{l}20-70 \text { (<5 marked decrease; } \\
5-10 \text { modest decrease; } \\
\text { 10-20 slight decrease; } \\
>200 \text { intoxication) }\end{array}$ & $14-46$ & $0-0.70$ & $\begin{array}{l}\text { 16.89-65.491 (pre-menopause, } \\
\text { 5.13-58.59; post-menopause } \\
\text { with HRT treatment, } \\
\text { 14.28-58.92; post-menopause } \\
\text { without HRT treatment, } \\
\text { 20.25-76.31) }\end{array}$ & $45-125$ \\
\hline
\end{tabular}

ALP, alkaline phosphatase; TPINP, total procollagen type $1 \mathrm{~N}$-terminal propeptide; HRT, hormone replacement therapy.

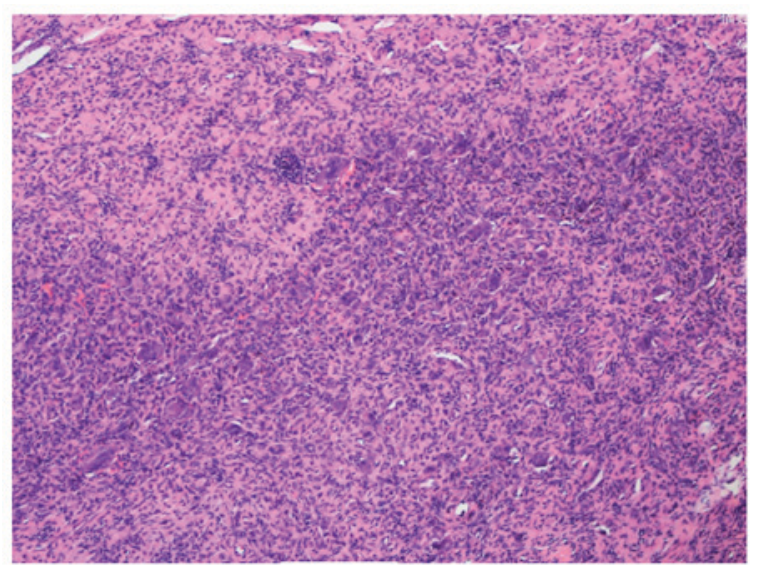

Figure 5. Histological examination of the phosphaturic mesenchymal tumor-mixed connective tissue in Case 1 exhibits swirling bundles of spindle cells with moderate atypia, greater mitotic activity, scattered multinucleated giant cells, and focal matrix production. A representative image is shown from hematoxylin \& eosin staining at x10 original magnification.

different bone-specific reaction patterns considered within the spectrum of PMT-MCTs (38-40). The classic microscopic characterization of a PMT-MCT is that of a variably

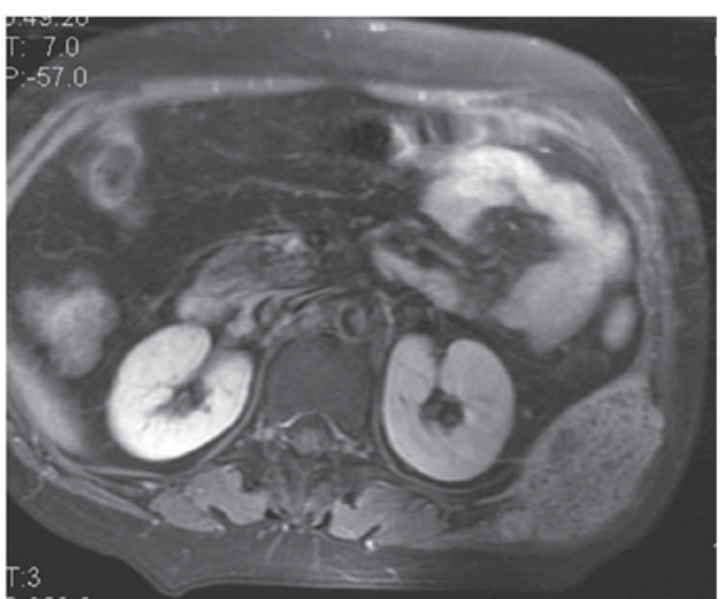

Figure 6. A phosphaturic mesenchymal tumor-mixed connective tissue with large tumor size $(14 \times 9 \times 8 \mathrm{~cm})$ displays markedly heterogeneous enhancement on fat-saturated T1-weighted sequence containing prominent vascular component.

prominent vascular proliferation of plump oval, spindled to stellate cells with generally low nuclear grade, and very low or usually absent mitotic activity. The spindled cells are 


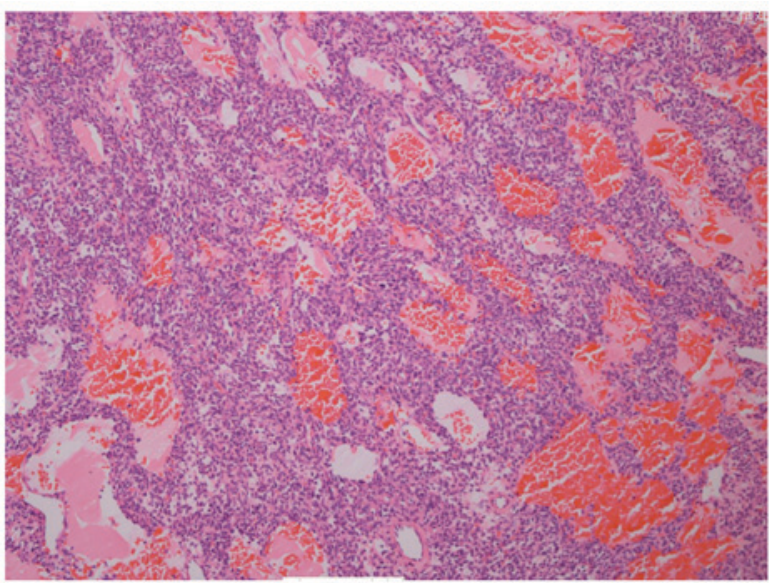

Figure 7. Histological examination of the phosphaturic mesenchymal tumor-mixed connective tissue in Case 2 exhibits bland spindle cells, prominent vascularity, and focal matrix production with stellate cells. A representative image is shown from hematoxylin \& eosin staining at x10 original magnification.

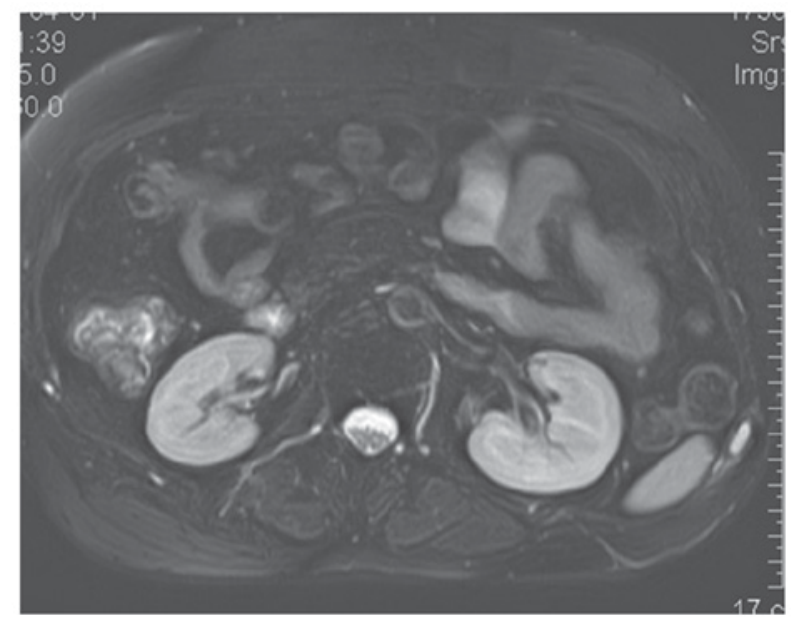

Figure 8. A phosphaturic mesenchymal tumor-mixed connective tissue with small tumor size $(1.5 \times 1.5 \times 0.5 \mathrm{~cm})$ located in the tenth intercostal space appears uniform hyperintense on fat-saturated T2-weighted imaging.

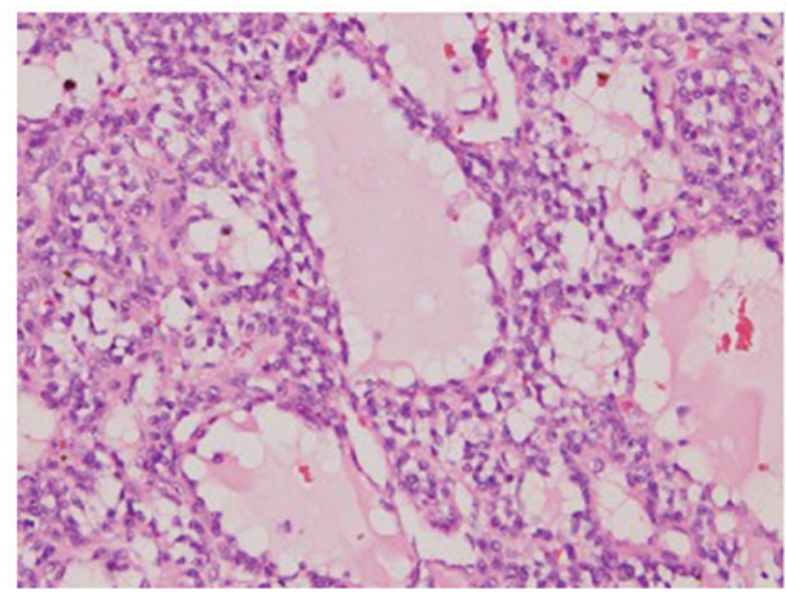

Figure 9. Histological examination of the phosphaturic mesenchymal tumor-mixed connective tissue in Case 3 reveals similar characteristics to Case 2, with bland spindle cells, prominent vessels, and a focal matrix production. A representative image is shown from hematoxylin \& eosin staining at $\mathrm{x} 10$ original magnification. typically embedded distinctively within a 'grungy', calcified, myxoid to chondromyxoid matrix and often include other findings, including osteoclast-like giant cells, mature fat cells, chondroid or osteoid-like matrix, poorly developed cartilage or bone, areas of hemorrhage and microcysts. Histopathology analysis reveals that pancytokeratin, desmin, S-100 and CD34 are not expressed in the tumor cells $(13,27,31,41,42)$, similar to what was observed in the present cases.

In order to identify the causative tumor of TIO, multiple noninvasive imaging techniques, such as ultrasonography, whole body CT and MRI, ${ }^{18} \mathrm{~F}$-FDG PET/CT, ${ }^{201} \mathrm{Tl}$ scintigraphy, ${ }^{99 \mathrm{~m} T c-M I B I}$ SPECT, ${ }^{99 \mathrm{~m}} \mathrm{Tc}$ bone scintigraphy, ${ }^{111} \mathrm{In}$-pentetreotide or octreotide scintigraphy, ${ }^{99 \mathrm{~m}} \mathrm{Tc}-\mathrm{HYNIC}-\mathrm{TOC}$ scan, and ${ }^{68} \mathrm{Ga}$-DOTATATE PET/CT have been pursued $(23,43-54)$. Recently, ${ }^{68} \mathrm{Ga}$-DOTANOC is firstly deemed as a sufficiently sensitive and specific in detecting an occult tumor $(43,46)$. In China, however, since somatostatin-based functional scans are not approved, ${ }^{18} \mathrm{~F}-\mathrm{FDG}$ PET/CT and ${ }^{99 \mathrm{~m}} \mathrm{Tc}$ bone scintigraphy are usually used when diagnosing mesenchymal tumors (55).

$C T$ and MR features and differential diagnosis. The majority of the published literature on imaging studies of PMTs is focused on the choice of optical imaging modality in localizing the tumor, not on the imaging features of PMTs. On CT scans, the tumor exhibits a round/oval, well-bordered, isodense/hypodense soft tissue mass and displays a uniform enhancement when the tumor is small $(45,56)$, similar to what was observed in the present cases. The typical MR appearances of PMT-MCT are isointense relative to the muscles on T1-weighted imaging and markedly hyperintense on T2-weighted imaging, with markedly homogenous enhancement on post contrast T1-weighted fat-suppression imaging. However, the variable tumor sizes result in different MRI imaging features. PMT-MCT with small tumor size displays homogenous signal intensity on both T2WI and T1WI and uniform enhancement on post-contrast T1WI. In contrast, a large tumor displays heterogeneous signal intensity on T2WI and T1WI and heterogeneous enhancement on post-contrast T1WI. The areas of heterogeneous low signals are consistent with vascular flow voids within large tumors.

Case 2 had a large chest mass and the tumor displayed an oval, poorly-bordered, isodense mass on CT scan, heterogeneously decreased signal intensity on T1WI, increased signal intensity on T2WI containing multiple abnormal tortuous vascular flow voids with a vivid enhancement, validated by pathology that the tumor contained prominently vascular components with abundant giant cells. The lesions were clearly depicted as high signal intensity on both STIR and diffusion weighted imaging (DWI), however, the findings were considered nonspecific. Since DWI may have resulted from T2 shine-through effect and has poor spatial resolution, high solution STIR sequence should be the optimal sequence in localizing the tumor $(8,57-59)$.

In the present cases, the neoplasms occurred in soft tissue and followed a benign clinical course. The differential possibilities for PMT-MCTs include any soft tissue mass, such as neurofibroma, hemangioendothelioma, fibroma, neurofibrosarcoma, hemangioma, leiomyoma, giant cell tumor, giant cell reparative granuloma, tenosynovitis, ganglion cyst, histiocytoma, desmoid tumor and neuroma. On the basis of 
histologic and pathologic findings, radiological features and the characteristic clinical signs, the neoplasms were concluded to be PMT-MCTs, which show similar morphology to those soft-tissue tumors previously reported.

To the best of our knowledge, this is the first report of radiological and histological description of a large PMT-MCT (Case 2), which arises from chest wall and causes oncogenic osteomalacia. Thus, it appears to be essential that this entity should be considered among the chest wall tumors.

Treatment and prognosis. The PMT-MCT frequently has an infiltrating growth pattern, as reported in the present cases, and this may explain the high rates of local recurrence (44,60-64). Early, complete surgical resection remains the definitive treatment of PMT-MCTs. It has been previously reported that $\sim 90 \%$ of patients with PMT-MCTs are cured by excision $(20,34,65-67)$. All three of the current patients were treated with surgery, which led to the normalization of serum phosphate levels and resolution of symptoms. A key point of surgery is the total removal of the tumor. Wide negative margins are essential for preventing local recurrence of PMT-MCTs, even though bone resection may be required. In addition, intralesional treatment is insufficient to control the tumors occurring in bone and radical resection should be planned. However, local recurrence and metastasis after surgical resection have been described. Although malignant transformation of PMT-MCTs is extremely rare (12), the patient experienced multiple recurrence and developed histologic features that were highly suggestive of high-grade status, hypercellularity, and increased mitotic activity transformation of primary benign tumors.

Medical therapy with phosphorus and calcitriol is often given after incomplete resection of the tumor, resulting in anatomic restrictions or medical comorbidities. Although somatostatin receptors have been identified on PMT-MCTs, octreotide therapy, which was based on decreasing FGF23 secretion, has not been effective. Periodic measurement of serum phosphate and FGF23 levels has been advocated as a means to detect recurrences $(3,60,68)$.

The prognosis for most patients with PMT-MCTs is good; however, a delay in the diagnosis and surgical treatment can increase the overall mortality rates associated with this tumor $(69,70)$.

In conclusion, the present report suggested that once patients have been diagnosed with oncogenic osteomalacia, a whole-body screening scan, such as ${ }^{68} \mathrm{Ga}$-DOTANOC or ${ }^{18} \mathrm{~F}$-FDG PET/CT, should be performed to search for the underlying causative tumor, especially when this occurs in an odd location. After identifying the tumor with functional imaging, anatomic imaging analysis, such as CT or MRI, should be used to investigate the radiological features of the tumor and define the exact location.

\section{Acknowledgements}

This study was supported by the Science and Technology Department of Fujian Province (grant no. 2016Y0039), the Health and Planning Committee of Fujian Province (grant no. 2016013), the Natural Science Foundation of Fujian province (grant no. 2015J01450) and the Fujian Provincial
Department of Finance (grant no. BPB-lym2014). The authors would like to thank Dr. Kamisha Ramen (Fujian Medical University, Fuzhou, Fujian, China) for her contribution to the language editing of the present manuscript.

\section{References}

1. Shiba E, Matsuyama A, Shibuya R, Yabuki K, Harada H, Nakamoto M, Kasai T and Hisaoka M: Immunohistochemical and molecular detection of the expression of FGF23 in phosphaturic mesenchymal tumors including the non-phosphaturic variant. Diagn Pathol 11: 26, 2016.

2. Nakamura K, Ohishi M, Matsunobu T, Nakashima Y, Sakamoto A, Maekawa A, Oda Y and Iwamoto Y: Tumor-induced osteomalacia caused by a massive phosphaturic mesenchymal tumor of the acetabulum: A case report. Mod Rheumatol 4: 1-5, 2016 (Epub ahead of print).

3. Hautmann AH, Schroeder J, Wild P, Hautmann MG, Huber E, Hoffstetter P, Fleck M and Girlich C: Tumor-induced osteomalacia: Increased level of FGF-23 in a patient with a phosphaturic mesenchymal tumor at the tibia expressing periostin. Case Rep Endocrino 2014: 729387, 2014.

4. Norden AG, Laing RJ, Rowe P, Unwin RJ, Wrong $O$ and Crisp AJ: Oncogenic osteomalacia, raised FGF-23 and renal Fanconi syndrome. QJM 107: 139-141, 2014.

5. Larsson T, Zahradnik R, Lavigne J, Ljunggren O, Jüppner H and Jonsson KB: Immunohistochemical detection of FGF-23 protein in tumors that cause oncogenic osteomalacia. Eur J Endocrinol 148: 269-276, 2003.

6. Dupond JL, Magy N, Mahammedi M, Prie D, Gil H, Meaux-Ruault N and Kantelip B: Oncogenic osteomalacia: The role of the phosphatonins. Diagnostic usefulness of the Fibroblast growth factor 23 measurement in one patient. Rev Med Interne 26: 238-241, 2005 (In French).

7. Nelson AE, Bligh RC, Mirams M, Gill A, Au A, Clarkson A, Jüppner H, Ruff S, Stalley P, Scolyer RA, et al: Clinical case seminar: Fibroblast growth factor 23: A new clinical marker for oncogenic osteomalacia. J Clin Endocrinol Metab 88: 4088-4094, 2003.

8. Qari H, Hamao-Sakamoto A, Fuselier C, Cheng YS, Kessler H and Wright J: Phosphaturic mesenchymal tumor: 2 New oral cases and review of 53 cases in the head and neck. Head Neck Pathol 10: 192-200, 2016.

9. Okamiya T, Takahashi K, Kamada H, Hirato J, Motoi T, Fukumoto S and Chikamatsu K: Oncogenic osteomalacia caused by an occult paranasal sinus tumor. Auris Nasus Larynx 42: $167-169,2015$.

10. Ledford CK, Zelenski NA, Cardona DM, Brigman BE and Eward WC: The phosphaturic mesenchymal tumor: Why is definitive diagnosis and curative surgery often delayed? Clin Orthop Relat Res 471: 3618-3625, 2013.

11. Chiam P, Tan HC, Bee YM and Chandran M: Oncogenic osteomalacia-hypophosphataemic spectrum from 'benignancy' to 'malignancy'. Bone 53: 182-187, 2013.

12. Morimoto T, Takenaka S, Hashimoto N, Araki N, Myoui A and Yoshikawa H: Malignant phosphaturic mesenchymal tumor of the pelvis: A report of two cases. Oncol Lett 8: 67-71, 2014.

13. William J, Laskin W, Nayar R and De Frias D: Diagnosis of phosphaturic mesenchymal tumor (mixed connective tissue type) by cytopathology. Diagn Cytopathol 40 (Suppl 2): E109-E113, 2012.

14. Guglielmi G, Bisceglia M, Scillitani A and Folpe AL: Oncogenic osteomalacia due to phosphaturic mesenchymal tumor of the craniofacial sinuses. Clin Cases Miner Bone Metab 8: 45-49, 2011.

15. Chong. WH, Molinolo AA, Chen CC and Collins MT: Tumor-induced osteomalacia. Endocr Relat Cancer 18: R53-R77, 2011.

16. Kaul M, Silverberg M, Dicarlo EF, Schneider R, Bass AR and Erkan D: Tumor-induced osteomalacia. Clin Rheumatol 26: 1575-1579, 2007.

17. Weidner N and Santa Cruz D: Phosphaturic mesenchymal tumors. A polymorphous group causing osteomalacia or rickets. Cancer 59: 1442-1454, 1987.

18. Gatti AP, Tonello L, Neto JA, Teixeira UF, Goldoni MB, Fontes PR, Sampaio JA, Lima LM and Waechter FL: Oncogenic hypophosphatemic osteomalacia: From the first signal of disease to the first signal of healthy. Int J Surg Case Rep 30: 130-133, 2017. 
19. Mok Y, Lee JC, Lum JH and Petersson F: From epistaxis to bone pain-report of two cases illustrating the clinicopathological spectrum of phosphaturic mesenchymal tumour with fibroblast growth factor receptor 1 immunohistochemical and cytogenetic analyses. Histopathology 68: 925-930, 2016.

20. Manara M and Sinigaglia L: 'Slow and steady wins the race': The importance of perseverance in the management of oncogenic osteomalacia. Endocrine 57: 1-2, 2017.

21. Leow MK, Hamijoyo L, Liew H, Thirugnanam U, Cheng MH, Loke KS, Teo MS, Chuah KL and Chng HH: Oncogenic osteomalacia presenting as a crippling illness in a young man. Lancet 384: 1236, 2014

22. Kaniuka-Jakubowska S, Biernat W and Sworczak K: Oncogenic osteomalacia and its symptoms: Hypophosphatemia, bone pain and pathological fractures. Postepy Hig Med Dosw (online) 66 554-567, 2012 (In Polish).

23. Chang CV, Conde SJ, Luvizotto RA, Nunes VS, Bonates MC, Felicio AC, Lindsey SC, Moraes FH, Tagliarini JV, Mazeto GM, et al: Oncogenic osteomalacia: Loss of hypophosphatemia might be the key to avoid misdiagnosis. Arq Bras Endocrinol Metabol 56: 570-573, 2012.

24. Ogose A, Hotta T, Emura I, Hatano H, Inoue Y, Umezu H and Endo N: Recurrent malignant variant of phosphaturic mesenchymal tumor with oncogenic osteomalacia. Skeletal Radiol 30: 99-103, 2001

25. Pallavi R, Ravella PM, Gupta P and Popescu A: A case of phosphaturic mesenchymal tumor. Am J Ther 22: e57-e61, 2015.

26. Fatani HA, Sunbuli M, Lai SY and Bell D: Phosphaturic mesenchymal tumor: A report of 6 patients treated at a single institution and comparison with reported series. Ann Diagn Pathol 17: 319-321, 2013

27. Suryawanshi P, Agarwal M, Dhake R, Desai S, Rekhi B, Reddy KB and Jambhekar NA: Phosphaturic mesenchymal tumor with chondromyxoid fibroma-like feature: An unusual morphological appearance. Skeletal Radiol 40: 1481-1485, 2011.

28. Akhter M, Sugrue PA, Bains R and Khavkin YA: Oncogenic osteomalacia of the cervical spine: A rare case of curative resection and reconstruction. J Neurosurg Spine 14: 453-456, 2011.

29. Sidell D, Lai C, Bhuta S, Barnes L and Chhetri DK: Malignant phosphaturic mesenchymal tumor of the larynx. Laryngoscope 121: 1860-1863, 2011.

30. Hendry DS and Wissman R: Case 165: Oncogenic osteomalacia. Radiology 258: 320-322, 2011

31. Shelekhova KV, Kazakov DV, Hes O, Treska V and Michal M: Phosphaturic mesenchymal tumor (mixed connective tissue variant): A case report with spectral analysis. Virchows Arch 448: 232-235, 2006

32. Folpe AL, Fanburg-Smith JC, Billings SD, Bisceglia M, Bertoni F, Cho JY, Econs MJ, Inwards CY, Jan de Beur SM Mentzel T, et al: Most Osteomalacia-associated mesenchymal tumors are a single histopathologic entity: An analysis of 32 cases and a comprehensive review of the literature. Am J Surg Pathol 28: 1-30, 2004

33. Lopresti M, Daolio PA, Rancati JM, Ligabue N, Andreolli A and Panella L: Rehabilitation of a patient receiving a large-resection hip prosthesis because of a phosphaturic mesenchyal tumor. Clin Pract 5: 814, 2015

34. Angeles-Angeles A, Reza-Albarrán A, Chable-Montero F, Cordova-Ramón JC, Albores-Saavedra J and Martinez-Benitez B Phosphaturic mesenchymal tumors. Survey of 8 cases from a single mexican medical institution. Ann Diagn Pathol 19: 375-380, 2015.

35. Honda R, Kawabata Y, Ito S and Kikuchi F: Phosphaturic mesenchymal tumor, mixed connective tissue type, non-phosphaturic variant: Report of a case and review of 32 cases from the Japanese published work. J Dermatol 41: 845-849, 2014.

36. Deep NL, Cain RB, McCullough AE, Hoxworth JM and Lal D: Sinonasal phosphaturic mesenchymal tumor: Case report and systematic review. Allergy Rhinol (Providence) 5: 162-167, 2014.

37. Papierska L, Ćwikła JB, Misiorowski W, Rabijewski M, Sikora K and Wanyura $\mathrm{H}$ : Unusual case of phosphaturic mesenchymal tumor. Pol Arch Med Wewn 123: 255-256, 2013.

38. Gardner KH, Shon W, Folpe AL, Wieland CN, Tebben PJ and Baum CL: Tumor-induced osteomalacia resulting from primary cutaneous phosphaturic mesenchymal tumor: A case and review of the medical literature. J Cutan Pathol 40: 780-784, 2013.

39. Graham RP, Hodge JC, Folpe AL, Oliveira AM, Meyer KJ, Jenkins RB, Sim FH and Sukov WR: A cytogenetic analysis of 2 cases of phosphaturic mesenchymal tumor of mixed connective tissue type. Hum Pathol 43: 1334-1338, 2012.
40. Bower RS, Daugherty WP, Giannini C and Parney IF: Intracranial phosphaturic mesenchymal tumor, mixed connective tissue variant presenting without oncogenic osteomalacia. Surg Neurol Int 3: 151, 2012.

41. Woo VL, Landesberg R, Imel EA, Singer SR, Folpe AL, Econs MJ, Kim T, Harik LR and Jacobs TP: Phosphaturic mesenchymal tumor, mixed connective tissue variant, of the mandible: Report of a case and review of the literature. Oral Surg Oral Med Oral Pathol Oral Radiol Endod 108: 925-932, 2009.

42. Reis-Filho JS, Paiva ME and Lopes JM: Pathologic quiz case. A 36-year-old woman with muscle pain and weakness. Phosphaturic mesenchymal tumor (mixed connective tissue variant)/oncogenic osteomalacia. Arch Pathol Lab Med 126: 1245-1246, 2002.

43. Singh D, Chopra A, Ravina M, Kongara S, Bhatia E, Kumar N, Gupta S, Yadav S, Dabadghao P, Yadav R, et al: Oncogenic osteomalacia: Role of Ga-68 DOTANOC PET/CT scan in identifying the culprit lesion and its management. Br J Radiol 90: $20160811,2017$.

44. Basu S and Fargose P: 177Lu-DOTATATE PRRT in recurrent skull-base phosphaturic mesenchymal tumor causing osteomalacia: A potential application of PRRT beyond neuroendocrine tumors. J Nucl Med Technol 44: 248-250, 2016.

45. Kaneuchi Y, Hakozaki M, Yamada H, Hasegawa O, Tajino T and Konno S: Missed causative tumors in diagnosing tumor-induced osteomalacia with (18)F-FDG PET/CT: A potential pitfall of standard-field imaging. Hell J Nucl Med 19: 46-48, 2016.

46. Agrawal K, Bhadada S, Mittal BR, Shukla J, Sood A, Bhattacharya A and Bhansali A: Comparison of 18F-FDG and 68Ga DOTATATE PET/CT in localization of tumor causing oncogenic osteomalacia. Clin Nucl Med 40: e6-e10, 2015.

47. Breer S, Brunkhorst T, Beil FT, Peldschus K, Heiland M, Klutmann S, Barvencik F, Zustin J, Gratz KF and Amling M: 68Ga DOTA-TATE PET/CT allows tumor localization in patients with tumor-induced osteomalacia but negative 111 In-octreotide SPECT/CT. Bone 64: 222-227, 2014

48. Jing H, Li F, Zhong D and Zhuang H: $99 \mathrm{~m} \mathrm{Tc-HYNIC-TOC}$ (99mTc-hydrazinonicotinyl-Tyr3-octreotide) scintigraphy identifying two separate causative tumors in a patient with tumor-induced osteomalacia (TIO). Clin Nucl Med 38: 664-667, 2013.

49. Nakanishi K, Sakai M, Tanaka H, Tsuboi H, Hashimoto J, Hashimoto $\mathrm{N}$ and Tomiyama N: Whole-body MR imaging in detecting phosphaturic mesenchymal tumor (PMT) in tumor-induced hypophosphatemic osteomalacia. Magn Reson Med Sci 12: 47-52, 2013.

50. Andreopoulou P, Dumitrescu CE, Kelly MH, Brillante BA, Cutler Peck CM, Wodajo FM, Chang R and Collins MT: Selective venous catheterization for the localization of phosphaturic mesenchymal tumors. J Bone Miner Res 26: 1295-1302, 2011.

51. Hodgson SF, Clarke BL, Tebben PJ, Mullan BP, Cooney WP III and Shives TC: Oncogenic osteomalacia: Localization of underlying peripheral mesenchymal tumors with use of Tc $99 \mathrm{~m}$ sestamibi scintigraphy. Endocr Pract 12: 35-42, 2006.

52. Kimizuka T, Ozaki Y and Sumi Y: Usefulness of $201 \mathrm{Tl}$ and $99 \mathrm{mTc}$ MIBI scintigraphy in a case of oncogenic steomalacia. Ann Nucl Med 18: 63-67, 2004.

53. Jan de Beur SM, Streeten EA, Civelek AC, McCarthy EF, Uribe L, Marx SJ, Onobrakpeya O, Raisz LG, Watts NB, Sharon M, et al: Localisation of mesenchymal tumours by somatostatin receptor imaging. Lancet 359: 761-763, 2002.

54. Reubi JC, Waser B, Laissue JA and Gebbers JO: Somatostatin and vasoactive intestinal peptide receptors in human mesenchymal tumors: In vitro identification. Cancer Res 56: 1922-1931, 1996.

55. Kong X, Liu Y, Li Y, Zhai Y and Wu Dan: Imaging diagnosis of tumor-induced osteomalacia. Chin J Med Imaging 22: 624-629, 2014 (In Chinese).

56. Cowan S, Lozano-Calderon SA, Uppot RN, Sajed D and Huang AJ: Successful CT guided cryoablation of phosphaturic mesenchymal tumor in the soft tissues causing tumor-induced osteomalacia: A case report. Skeletal Radiol 46: 273-277, 2017.

57. Fukumoto S, Takeuchi Y, Nagano A and Fujita T: Diagnostic utility of magnetic resonance imaging skeletal survey in a patient with oncogenic osteomalacia. Bone 25: 375-377, 1999.

58. Avila NA, Skarulis M, Rubino DM and Doppman JL: Oncogenic osteomalacia: Lesion detection by MR skeletal survey. AJR Am J Roentgenol 167: 343-345, 1996.

59. Monappa V, Naik AM, Mathew M, Rao L, Rao SK, Ramachandra L and PadmaPriya J: Phosphaturic mesenchymal tumour of the mandible-the useful criteria for a diagnosis on fine needle aspiration cytology. Cytopathology 25: 54-56, 2014. 
60. Ulas A, Dede DS, Sendur MA, Akinci MB and Yalcin B Expectations of response from octreotide therapy in recurrent phosphaturic mesenchymal tumors-do they reflect reality? Asian Pac J Cancer Prev 15: 10997-10998, 2014.

61. Dezfulian M and Wohlgenannt O: Revision hip arthroplasty following recurrence of a phosphaturic mesenchymal tumor. J Surg Case Rep 9: pii: rjt059, 2013.

62. Allevi F, Rabbiosi D, Mandalà M and Colletti G: Mesenchymal phosphaturic tumour: Early detection of recurrence. BMJ Case Rep 2014: bcr2013202827, 2014.

63. Kimura S, Yanagisawa M, Fujita Y, Sakihara S, Hisaoka M and Kurose A: A case of phosphaturic mesenchymal tumor of the pelvis with vascular invasion. Pathol Int 65: 510-512, 2015.

64. Syed MI, Chatzimichalis M, Rössle M and Huber AM: Recurrent phosphaturic mesenchymal tumour of the temporal bone causing deafness and facial nerve palsy. J Laryngol Otol 126: 721-724, 2012.

65. Okiror L, Khalil H, Vaiyapuri S and Kalkat M: Complete resection of a large phosphaturic mesenchymal tumour by chest wall resection and reconstruction. Gen Thorac Cardiovasc Surg 64: 355-358, 2016.

66. Farmakis SG and Siegel MJ: Phosphaturic mesenchymal tumor of the tibia with oncogenic osteomalacia in a teenager. Pediatr Radiol 45: 1423-1426, 2015.
67. Tarasova VD, Trepp-Carrasco AG, Thompson R, Recker RR, Chong WH, Collins MT and Armas LA: Successful treatment of tumor-induced osteomalacia due to an intracranial tumor by fractionated stereotactic radiotherapy. J Clin Endocrinol Metab 98: 4267-4272, 2013.

68. Chong WH, Andreopoulou P, Chen CC, Reynolds J, Guthrie L, Kelly M, Gafni RI, Bhattacharyya N, Boyce AM, El-Maouche D, et al: Tumor localization and biochemical response to cure in tumor-induced osteomalacia. J Bone Miner Res 28: 1386-1398, 2013.

69. Imanishi Y, Hashimoto J, Ando W, Kobayashi K, Ueda T, Nagata Y, Miyauchi A, Koyano HM, Kaji H, Saito T, et al: Matrix extracellular phosphoglycoprotein is expressed in causative tumors of oncogenic osteomalacia. J Bone Miner Metab 30: 93-99, 2012.

70. Jiang Y, Xia WB, Xing XP, Silva BC, Li M, Wang O, Zhang HB, Li F, Jing HL, Zhong DR, et al: Tumor-induced osteomalacia: An important cause of adult-onset hypophosphatemic osteomalacia in China: Report of 39 cases and review of the literature. J Bone Miner Res 27: 1967-1975, 2012.

(i) (5) This work is licensed under a Creative Commons Attribution-NonCommercial-NoDerivatives 4.0 International (CC BY-NC-ND 4.0) License. 